Hill and Upland Livestock Production

Occusional Publication No. 10-British Society of Animal Production 1985

edited by T. J. Maxwell and R. G. Gunn

\title{
LAMB MARKETING IN THE HILLS AND UPLANDS
}

\author{
J. K. S. VOLANS
}

Edinburgh School of Agriculture, 6 South Oswald Road, Edinburgh

$\mathbf{T}$

This paper considers the current support and market position for lamb and relates these to the position of sheep producers in the hills and uplands.

Since 1980, when the EEC Sheep Meat Regime was introduced, returns to UK sheep producers have increased annually at a much higher rate than for other sheep meat producers in the EEC, and well above the rate for other CAP commodities. This position has now changed. Transition to a common level of support was completed in 1984/85. In future, support price increases are likely to be modest and support price levels are likely to fall in real terms. For example, the 1985 Price Review resulted in no increases in support prices for the latter part of 1985 and only a $1 \%$ increase in 1986 . In this situation, with support prices falling in real terms, returns from the market will become more important to producers.

There have also been developments in the nature of the market facing producers, with a general trend towards increased sales through multiple retailers and supermarkets - and an associated change in the demand from carcass meat to a demand for cuts and processed lamb products. Until recently, most lamb was supplied to retailers in carcass form, which meant that the cost of any wastage in processing was borne by the retailer and only indirectly by the wholesaler or producer. Many retailers would now like to change this situation by reducing the amount of processing they carry out, not only becausc it is costly but also because of the difficulty of controlling margins between different depots and shops. They would therefore like to purchase an increased proportion of their supplies in a processed form, i.e. bone-out or in retail packs, in some instances down to labelling and pricing.

Variations in quality and yield will be passed back to the wholesaler/slaughterer, who will in turn pass them back to the producer in the form of tighter procurement specifications and/or lower prices.

These developments will therefore require greater precision in livestock production and marketing/ procurement, the use of an improved system of classification and the better feedback of price and carcass information to producers. They will also lead to a further concentration of meat processing facilities and lamb production will have to become more tailored to the marketing of specific types of lamb to specified outlets - and the availability of these outlets will become important.

These developments are particularly important for the hills and uplands, where large volume buyers, such as multiple retailers and supermarkets, and Continental export buyers, are important. MLC classification data would also suggest that there is significant room for improvement in the type of lamb produced in these areas, in terms of consistency and the reduction in fat levels.

Producers in the hills and uplands will therefore have to pay more attention to getting better information back on the stock they produce so that they can select for leanness and weight, to increase saleable meat yield and reduce processing costs. Producers will also need to negotiate prices which reflect the growing retail market demand for leaner lambs, encourage abattoirs to adopt quality assurance schemes and ensure their local slaughtering and meat processing facilities are of a high standard, able to cope with an increased demand for a high level of processing and packaging. Without such improved processing facilities and improved lamb supplies, the competitive position of producers in these areas will decline, market prices will fall further below the national average and, with a static or declining level of market support, producers' returns will fall.

\section{REFERENCES}

Volans, J. K. S. 1985. Future prospects for UK sheep producers. ESCA Technical Note No. 37I, January.

VoLANS, J. K. S. 1985. Lamb marketing strategy building a market for lamb. ESCA Technical Note No. 376, April. 